\title{
Expression of obesity-related miR-1908 in human adipocytes is regulated by adipokines, free fatty acids and hormones
}

\author{
XINYE JIANG $^{1 *}$, LEI YANG ${ }^{2,3 *}$, LINGXIA PANG ${ }^{2,3}$, LING CHEN $^{2,3}$, \\ XIRONG GUO ${ }^{2,3}, \mathrm{CHENBO} \mathrm{JI}^{3}, \mathrm{CHUNMEI} \mathrm{SHI}^{2,3}$ and YUHUI NI ${ }^{2}$ \\ ${ }^{1}$ Department of Child Health Care, Wuxi Maternal and Child Health Hospital, Wuxi, Jiangsu 214002; \\ ${ }^{2}$ Institute of Pediatrics, Nanjing Medical University; ${ }^{3}$ Department of Child Health Care, \\ Nanjing Maternity and Child Health Care Hospital Affiliated to Nanjing Medical University, \\ Nanjing, Jiangsu 210029, P.R. China
}

Received September 23, 2013; Accepted April 28, 2014

DOI: $10.3892 / \mathrm{mmr} .2014 .2297$

\begin{abstract}
White adipose tissue mass is governed by competing processes that control lipid synthesis and storage, as well as the development of new adipocytes, and also trigger metabolic and inflammatory changes. microRNAs (miRNAs) have been suggested to act as negative regulators controlling varied biological processes at the level of post-transcriptional repression. The present study focused on investigating the expression of miR-1908 in mature human adipocytes and its responses to adipokines [tumor necrosis factor $\alpha(\mathrm{TNF}-\alpha)$, interleukin 6 (IL-6), leptin and resistin), free fatty acids (FFAs), growth hormone $(\mathrm{GH})$ and dexamethasone (DEX). miR-1908 was highly expressed in mature human adipocytes. The mature human adipocytes responded to proinflammatory cytokines (TNF- $\alpha$ and IL-6) by markedly increasing the expression of miR-1908 at $4 \mathrm{~h}$ of incubation. Adipokines (resistin and leptin) and FFAs were shown to downregulate the expression of miR-1908 in human adipocytes. Furthermore, the expression of miR-1908 was decreased $4 \mathrm{~h}$ after treatment with $\mathrm{GH}$; however, DEX treatment of human adipocytes did not affect the expression of miR-1908 during the 24-h experimental period. In conclusion, the present study showed that the expression of miR-1908 is affected by a variety of factors that are associated with obesity and insulin sensitivity. miR-1908 may be an important mediator in the development of obesity-related complications.
\end{abstract}

Correspondence to: Dr Yuhui Ni or Dr Chunmei Shi, Institute of Pediatrics, Nanjing Medical University, Xianzhi Building 1710, 140 Hanzhong Road, Nanjing, Jiangsu 210029, P.R. China

E-mail: niyuhui @hotmail.com

E-mail: chunmeishi@njmu.edu.cn

${ }^{*}$ Contributed equally

Key words: adipocytes, miR-1908, adipokines, FFAs, hormones, obesity

\section{Introduction}

The prevalence of obesity in children and adolescents is currently the major risk factor for the development of type 2 diabetes, heart disease, hypertension and stroke (1). Obesity occurs due to a positive energy balance in the body, which results in an increase in adipose tissue by an increase in either the number or the size of adipocytes (2). The expansion of adipose tissue that is associated with obesity eventually leads to adipose tissue dysfunction. The functions of adipose tissue are essential to energy metabolism as the tissue is not only an energy depot (3), but also a source of endocrine factors $(4,5)$, secreting adipokines, free fatty acids (FFAs) and hormones. Increasing evidence has shown that adipokines, including tumor necrosis factor $\alpha$ (TNF- $\alpha$ ), interleukin 6 (IL-6), leptin and resistin, are associated with obesity, inflammation and insulin resistance $(6,7)$. However, the molecular mechanisms underlying the effects of adipokines, FFAs and hormones on obesity and insulin sensitivity are elusive.

Over the past decade, microRNAs (miRNAs) have been shown to be involved in multiple biological processes, including glucose homeostasis and lipid metabolism $(8,9)$. A number of miRNAs have been identified that appear to have a role in obesity and insulin sensitivity. For example, in vertebrates, miR-375 and miR-376, which are abundantly expressed in pancreatic $\beta$-cells, are involved in the control of insulin secretion (10). Furthermore, miR-34a overexpression was shown to decrease glucose-stimulated insulin secretion and mediate FFA-induced apoptosis in Min6 cells by targeting vesicle-associated membrane protein 2 and B-cell lymphoma 2, respectively (11). However, there is still little evidence regarding the expression of miRNAs in adipose tissue, particularly the association between their regulation and obesity and insulin sensitivity.

miR-1908 was first identified in human embryonic stem cells in 2008 (12). To the best of our knowledge, the present study is the first functional study of miR-1908. In this study, it was found that miR-1908 was highly expressed in mature human adipocytes. Thus, it was hypothesized in the present study that adipokines, FFAs and hormones may participate in regulating the miR-1908 expression involved in 
the development of obesity. To evaluate this hypothesis, the expression of miR-1908 in mature human adipocytes was examined and its responses to adipokines, FFAs and hormones were investigated to clarify the role of miR-1908 in regulating the development of obesity and insulin resistance.

\section{Materials and methods}

Cell culture. Human visceral preadipocytes (ScienCell Research Laboratories, San Diego, CA, USA) were maintained in preadipocyte medium (PAM; cat. no. 7211; ScienCell Research Laboratories) containing 5\% fetal bovine serum, $1 \%$ preadipocyte growth supplement and $1 \%$ penicillin/streptomycin solution at $37^{\circ} \mathrm{C}$ in a humidified atmosphere under $5 \% \mathrm{CO}_{2}$. To induce differentiation, serum-free PAM [containing $50 \mathrm{nM}$ insulin (Sigma-Aldrich, St. Louis, MO, USA), $100 \mathrm{nM}$ dexamethasone (DEX; Sigma-Aldrich), $0.5 \mathrm{mM}$ 3-isobutyl-1-methylxanthine (Sigma-Aldrich) and $100 \mu \mathrm{M}$ rosiglitazone (Sigma-Aldrich)] was added to confluent human preadipocytes (day 0) and the medium was replaced every two days over four days. Thereafter, the medium was replaced with serum-free PAM containing $50 \mathrm{nM}$ insulin, which was replaced every two days until lipid droplets had accumulated in the cells (day 15). Fat accumulation was assessed by staining formalin-fixed cells with Oil Red O (Sigma-Aldrich). The cells were collected at different time-points (days 0 and 15).

Treatment of adipocytes with adipokines, FFAs and hormones. Differentiated adipocytes were used for experiments 15 days after the induction of differentiation, at which point $>80 \%$ of cells showed the morphological and biochemical properties of adipocytes. Following overnight incubation in serum-free PAM, human adipocytes were treated with different adipokines, including $10 \mathrm{ng} / \mathrm{ml}$ TNF- $\alpha$ (13), $30 \mathrm{ng} / \mathrm{ml}$ IL-6 (14), $30 \mathrm{ng} / \mathrm{ml} \mathrm{leptin}$ or $60 \mathrm{ng} / \mathrm{ml}$ resistin, $1 \mathrm{mmol} / \mathrm{l}$ FFA cocktail (lauric, myristic, linoleic, oleic and arachidonic acids), $1 \mathrm{mmol} / 1 \mathrm{DEX}$ or $100 \mathrm{nmol} / 1$ growth hormone (GH) (all adipokines, Sigma-Aldrich) for different periods of time (4, 8 and $24 \mathrm{~h}$ ). Adipocytes were collected at these time-points and prepared for further investigation.

$R N A$ isolation and quantitative polymerase chain reaction $(q P C R)$. Total RNA from human adipocytes was purified using TRIzol ${ }^{\circledR}$ (Invitrogen Life Technologies, Carlsbad, CA, USA) according to the manufacturer's instructions, followed by DNase I treatment (Takara Bio Inc., Shiga, Japan). The quality and concentration of the RNA was assessed using a Nanodrop 2.0 instrument (Thermo Fisher Scientific, Inc., Waltham, MA, USA). To monitor levels of miRNA, cDNA was synthesized from $200 \mathrm{ng}$ total RNA using the TaqMan ${ }^{\circledR}$ miRNA Reverse Transcription kit (Applied Biosystems, Foster City, CA, USA). qPCR was performed using a 7500 Sequence Detection system (Applied Biosystems), following the manufacturer's instructions. Briefly, samples were incubated at $95^{\circ} \mathrm{C}$ for $10 \mathrm{~min}$ for an initial denaturation stage, followed by $40 \mathrm{PCR}$ cycles consisting of incubation at $95^{\circ} \mathrm{C}$ for $15 \mathrm{sec}$ and then $60^{\circ} \mathrm{C}$ for 1 min. miRNA expression was normalized to small nuclear RNA (snRNA) U6 and miR-103, respectively. The primer identification numbers were 121109 for miR-1908, 000439 for miR-103 and 001973 for snRU6 (Applied Biosystems).

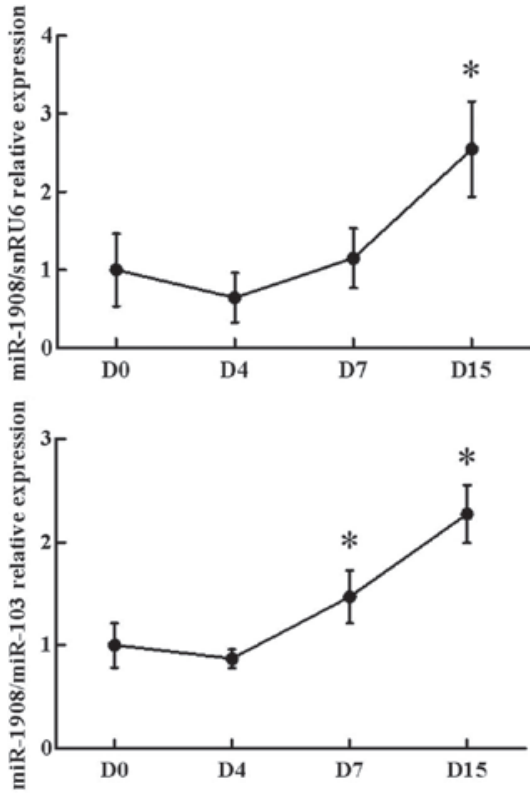

Figure 1. Expression of miR-1908 during the conversion of human preadipocytes (day 0) into adipocytes (day 15). Human preadipocytes were induced to differentiate and total RNA was harvested from the human preadipocytes on alternate days prior to (day 0 ) and after (day 15) replacement of growth medium with differentiation medium. miR-1908 and miR-103 levels were assessed using quantitative polymerase chain reaction and normalized to snRU6, and miR-1908 levels were also normalized to the levels of miR-103. The results are presented as the mean \pm standard error of the mean of three experiments. ${ }^{*} \mathrm{P}<0.01$ versus the basal levels (day 0). miR, micro RNA; snR, small nuclear RNA.

Statistical analysis. Representatives of replicate experiments are shown in the figures, and results are presented as the mean \pm standard error of the mean. Statistical analysis was performed using the one-way analysis of variance. $\mathrm{P} \leq 0.05$ was considered to indicate a statistically significant difference.

\section{Results}

miR-1908 expression is increased during differentiation of human preadipocytes. The present study firstly investigated the expression levels of miR-1908 during the maturation of human preadipocytes. As shown in Fig. 1, the miR-1908 expression levels were relatively low in human pre-adipocytes. Fifteen days after the induction of differentiation, $>80 \%$ of preadipocytes exhibited typical adipocyte morphology. In addition to miR-1908 levels, the expression levels of miR-103 were analyzed. miR-103 expression levels were not altered during the differentiation of the human preadipocytes. Thus, miR-103 was used as a normalization control for the assessment of miR-1908 expression. Using snRU6 and miR-103 as positive controls, miR-1908 expression levels were observed to be significantly upregulated in the cells at days 7 and 15 relative to those at day 0 . This observation demonstrated that miR-1908 expression was elevated during the differentiation of human preadipocytes into adipocytes.

miR-1908 is regulated by adipokines (IL-6, TNF- $\alpha$, leptin and resistin) in human adipocytes. Without any treatment, expression levels of miR-1908 remained unchanged at different time-points (4, 8 and 24 h) (Fig. 2). Thus, the expression at 

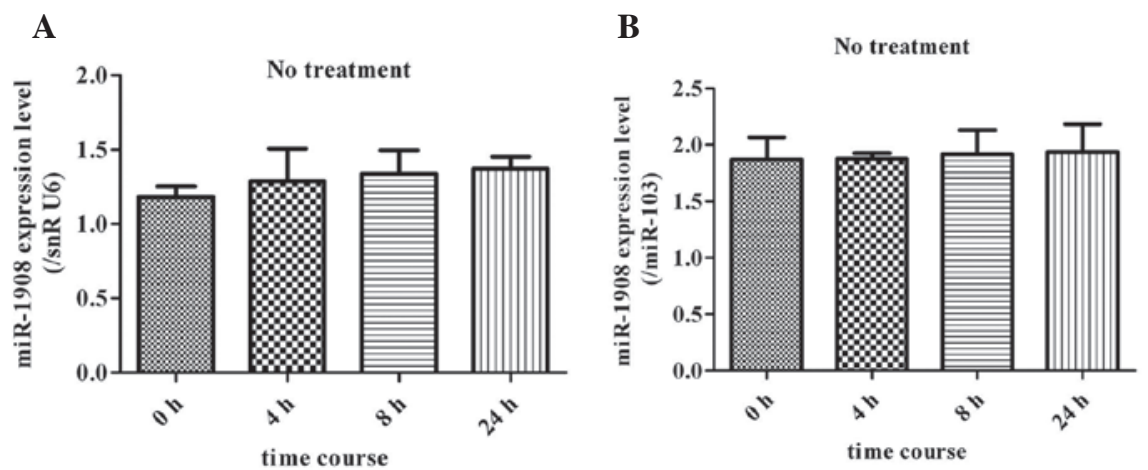

Figure 2. Alterations in miR-1908 expression levels at different time-points without any treatment. miR-1908 expression levels remained unchanged at different time-points (4, 8 and $24 \mathrm{~h}$ ), as indicated by quantitative polymerase chain reaction. Levels were normalized to the (A) snRU6 and (B) miR-103 levels. Results are expressed as the mean \pm standard error of the mean of three experiments. miR, microRNA; D, day; snR, small nuclear RNA.
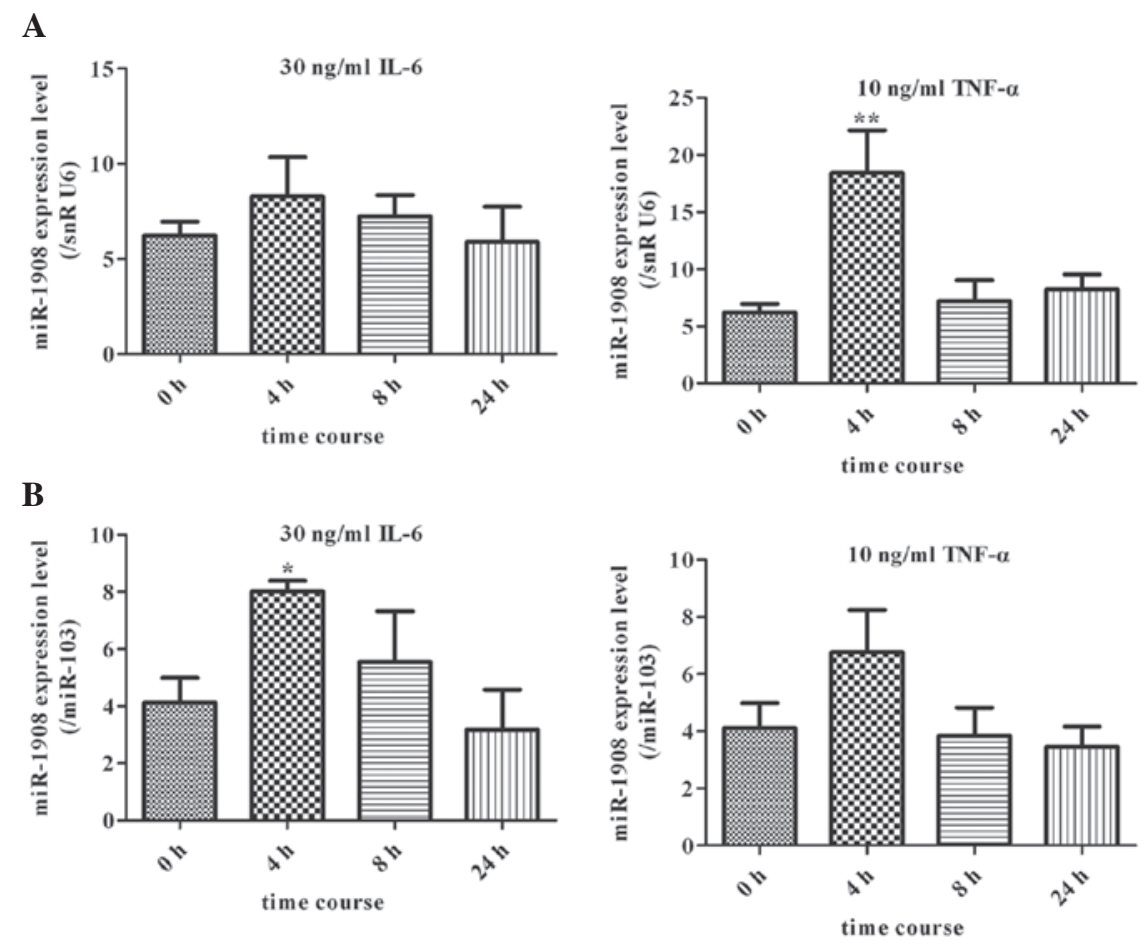

Figure 3. Inflammatory cytokines increase the expression of miR-1908 in human adipocytes. Cells were treated with IL-6 (30 ng/ml) and TNF- $\alpha$ (10 ng/ml), respectively, and miR-1908 expression was analyzed by quantitative polymerase chain reaction and normalized to (A) snRU6 and (B) miR-103 levels. ${ }^{*} \mathrm{P}<0.05$ and ${ }^{* *} \mathrm{P}<0.01$ versus the cells at $0 \mathrm{~h}$ (untreated cells). Data shown are representative of three separate experiments. Results are expressed as the mean \pm standard error of the mean. TNF- $\alpha$, tumor necrosis factor- $\alpha$; IL-6, interleukin 6; miR, micro RNA; snR, small nuclear RNA.

$0 \mathrm{~h}$ was used as a control during the assessment of miR-1908 expression. To assess the role of this miRNA in the association between obesity and insulin resistance, the effects of adipokines, including proinflammatory cytokines (TNF- $\alpha$ and IL-6), leptin and resistin, on the expression of miR-1908 in human adipocytes were assessed at different time-points (4, 8 and 24 h) (Figs. 3 and 4). When mature adipocytes were

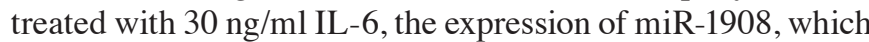
was normalized to snRU6 expression, was not significantly altered at the different time-points $(4,8$ and $24 \mathrm{~h})$. By contrast, it was observed that miR-1908 expression levels in human adipocytes treated with $10 \mathrm{ng} / \mathrm{ml} \mathrm{TNF}-\alpha$ were significantly upregulated at $4 \mathrm{~h}$ as compared with levels in the controls $(\mathrm{P}<0.05)$ (Fig. 3A). In addition, human adipocytes were treated with the adipokines leptin $(30 \mathrm{ng} / \mathrm{ml})$ and resistin $(60 \mathrm{ng} / \mathrm{ml})$. Of note, this led to $\sim 10$-fold decreases $(\mathrm{P}<0.01)$ in the expression of miR-1908 at $4 \mathrm{~h}$, with expression remaining low at $24 \mathrm{~h}$ of incubation (Fig. 4A). In summary, exposure of the cells to the adipokines leptin and resistin resulted in a decrease in the expression levels of miR-1908 (Fig. 4A). To further verify the effect of the aforementioned adipokines on miR-1908, miR-103 was also used for normalization, and the results were consistent with those obtained using snRU6 for normalization (Fig. 3B and 4B).

Effects of FFAs on miR-1908 expression in human adipocytes. The effects of $1 \mathrm{mmol} / \mathrm{l}$ FFAs on miR-1908 expression in cultured human adipocytes were analyzed using qPCR 
A

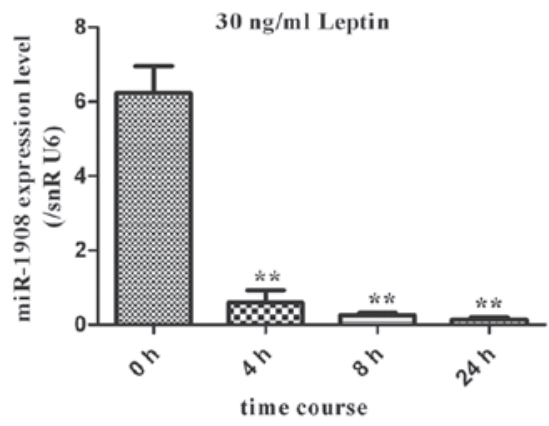

B

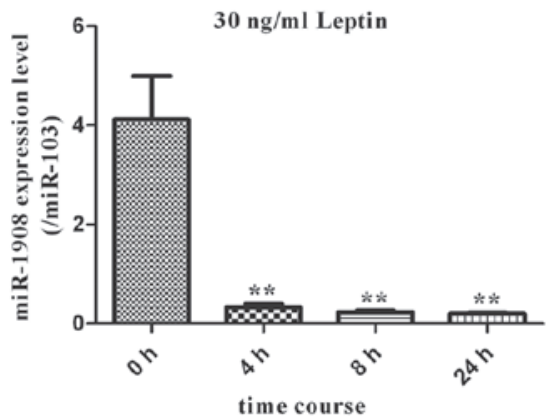

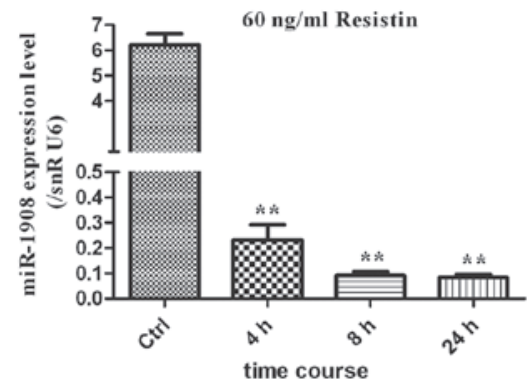

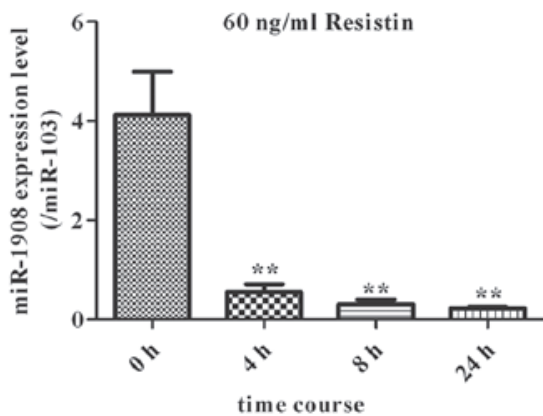

Figure 4. miR-1908 expression is regulated by adipokines (leptin and resistin) in human adipocytes. Differentiated human adipocytes were treated with $30 \mathrm{ng} / \mathrm{ml}$ leptin or $60 \mathrm{ng} / \mathrm{ml}$ resistin for the indicated periods (up to $24 \mathrm{~h}$ ). miR-1908 levels were analyzed by quantitative polymerase chain reaction and normalized to the (A) snRU6 and (B) miR-103 levels. Results are presented as the mean \pm standard error of the mean of three experiments. ${ }^{* *} \mathrm{P}<0.01$ versus the miR-1908 levels at 0 h (untreated cells). miR, micro RNA; Ctrl, control; snR, small nuclear RNA.
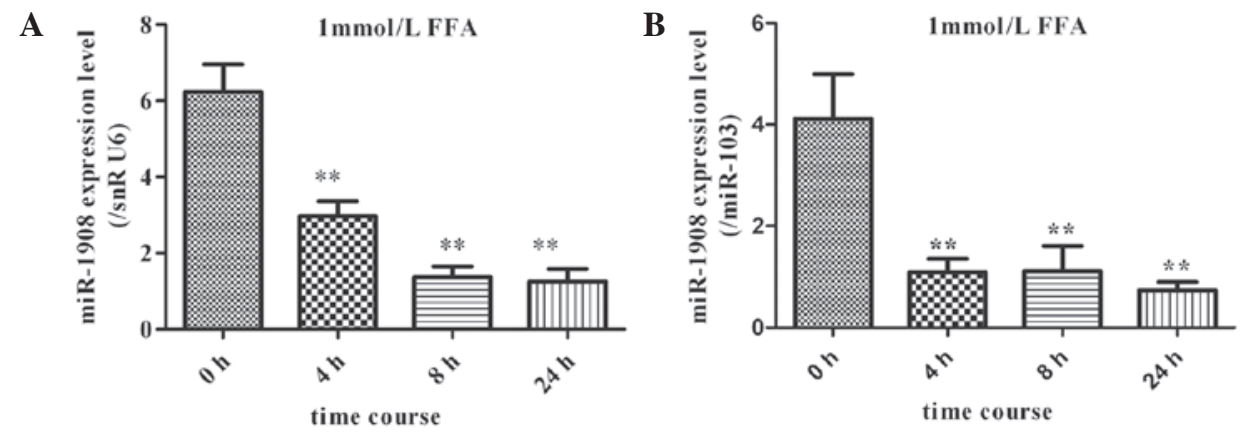

Figure 5. Effects of FFAs on miR-1908 expression in human adipocytes. Differentiated human adipocytes were treated with 1 mmol/1 FFAs for the indicated periods (up to $24 \mathrm{~h}$ ). miR-1908 expression was analyzed using quantitative polymerase chain reaction and normalized to the (A) snRU6 and (B) miR-103 levels. ${ }^{* *} \mathrm{P}<0.01$ versus the miR-1908 levels at $0 \mathrm{~h}$ (untreated cells). The data shown are representative of three similar experiments. Results are presented as the mean \pm standard error of the mean. FFA, free fatty acid; miR, micro RNA; snR, small nuclear RNA.

(TaqMan probe method). Differentiation of human preadipocytes was induced and adipocyte cultures were prepared for use in experiments, as described in the materials and methods. Adipocytes were cultured in the presence of $1 \mathrm{mmol} / \mathrm{l} \mathrm{FFAs}$. The expression of miR-1908 was significantly downregulated in a time-dependent manner following initiation of FFA stimulation. This effect was maintained for up to 24 h (Fig. 5).

Response of miR-1908 expression levels to DEX and GH in human adipocytes. The effects of DEX and GH on the expression of miR-1908 in human adipocytes were investigated. Mature adipocytes were cultured in the presence of $1 \mathrm{mmol} / \mathrm{l}$ DEX and the effects of DEX on miR-1908 expression in cultured human adipocytes were analyzed using qPCR (TaqMan probe method). The expression of miR-1908 was slightly altered by stimulation with DEX; however, no statistically significant differences in expression were observed compared with expression at $0 \mathrm{~h}$. In addition, miR-1908 expression in human adipocytes treated with $100 \mathrm{nmol} / \mathrm{l} \mathrm{GH}$ for different periods of time $(4,8$, and $24 \mathrm{~h})$ was investigated. As shown in Fig. 6, miR-1908 was significantly downregulated $4 \mathrm{~h}$ after the initiation of GH stimulation. Thereafter, the expression levels of miR-1908 slightly increased to equal those of untreated cells.

\section{Discussion}

Research into the association between obesity and its related complications, including type 2 diabetes and cardiovascular diseases, has indicated that adipose tissue plays a key role in the regulation of glucose and lipid metabolism, acting through at least two different mechanisms: i) Storage of lipids (as triglycerides) and ii) adipokine secretion, for endocrine 
A

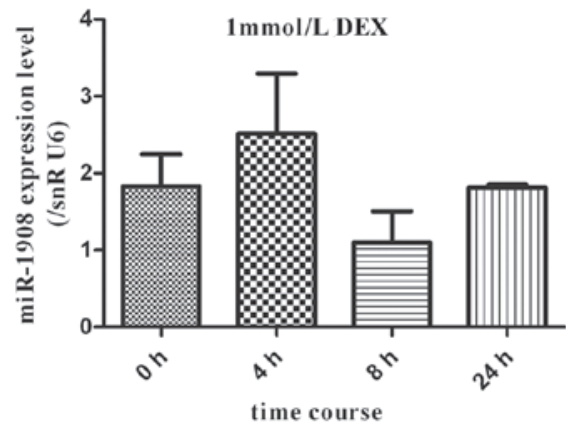

B

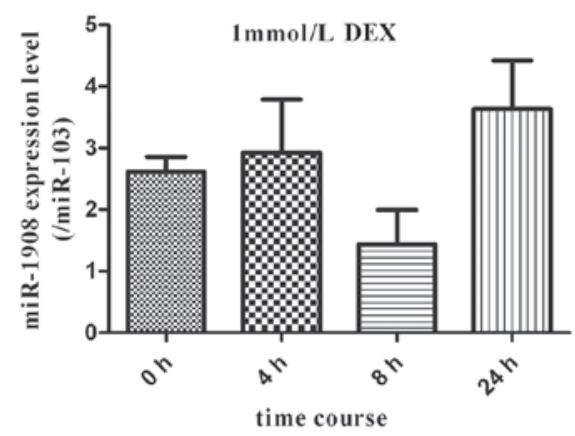

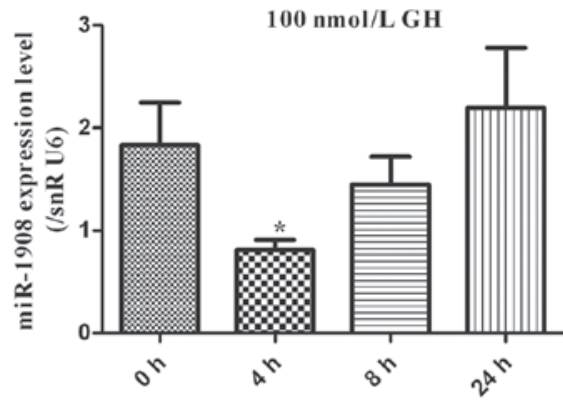

time course

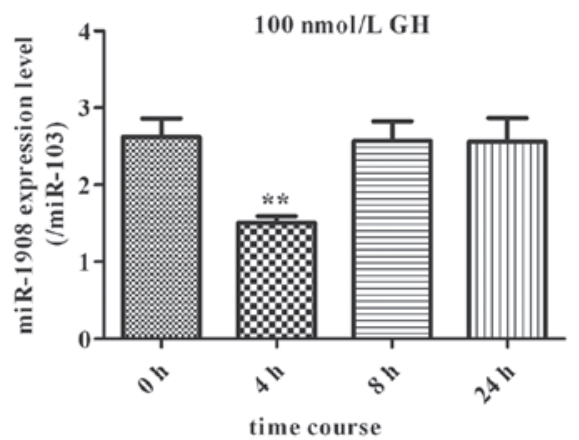

Figure 6. Response of miR-1908 expression levels to DEX and GH in human adipocytes. Differentiated human adipocytes were treated with 1 mmol/1 DEX or $100 \mathrm{nmol} / 1 \mathrm{GH}$ for the indicated periods (up to $24 \mathrm{~h}$ ). miR-1908 levels were assessed using quantitative polymerase chain reaction and normalized to the (A) snRU6 and (B) miR-103 levels. Results are expressed as the mean \pm standard error of the mean of three experiments. ${ }^{*} \mathrm{P}<0.05$ and ${ }^{* *} \mathrm{P}<0.01$ versus miR-1908 levels at 0 h (untreated cells). DEX, dexamethasone; GH, growth hormone; miR, micro RNA; snR, small nuclear RNA.

or paracrine signaling (15). The expansion of adipose tissue in obese individuals not only affects the storage of lipids as triglycerides in lipid droplets, but also results in qualitative and quantitative changes in a number of adipokines, including IL-6, TNF- $\alpha$, leptin and resistin (16). miRNAs are currently of particular interest in research on obesity and metabolic syndrome, and it was found that the dysregulation of miRNA expression is closely associated with these diseases. However, there is still no evidence regarding the expression of miRNAs in adipose tissue, particularly concerning the association between their regulation and obesity. In the present study, the role of miRNAs in obesity and insulin resistance was investigated.

miR-1908 was first identified in human embryonic stem cells in 2008 (12), and has since been found to be closely associated with the processes of metastatic invasion, angiogenesis and the colonization of melanomas (17). miR-1908 may also be involved in the malignant progression of chordoma (18) and may participate in the formation of hepatoma cells (19). The function of miR-1908 in adipocytes has yet to be elucidated. The present study showed that miR-1908 is highly expressed in human adipocytes. The effects of adipokines, FFAs and hormones associated with obesity, as well as obesity-related insulin resistance, on miR-1908 expression were investigated in human adipocytes.

It is well known that IL-6 production by adipose tissue is enhanced in obese patients (20). A previous study reported that TNF- $\alpha$ inhibited 3T3-L1 adipocyte differentiation by upregulating miR-155 expression (21). In the present study, miR-1908 expression levels were significantly upregulated in human adipocytes following treatment with $10 \mathrm{ng} / \mathrm{ml}$
TNF- $\alpha$ at 4 h; however, IL-6 had no statistically significant effect on miR-1908 expression. Resistin, also known as adipocyte-secreted factor and 'found in inflammatory zone 3', is a protein whose expression is adipocyte-specific in mice $(6,22,23)$. Leptin is an adipocyte-derived hormone and cytokine that is upregulated in patients with obesity-related type 2 diabetes mellitus, although leptin resistance may also occur (24). These two adipokines control food intake and energy expenditure. The functions of leptin and resistin have yet to be fully elucidated; however, there is evidence that these adipokines have a role in obesity-related insulin resistance as well as adipocyte differentiation $(6,22)$. In the present study, it was of note that marked decreases in the expression of miR-1908 were observed with the administration of leptin and resistin. This indicates that miR-1908 is closely associated with the development of obesity.

Plasma FFA concentrations are usually elevated in obese individuals (25), which may lead to several components of the insulin resistance syndrome and a risk of diabetes (26). In the present study, the expression of miR-1908 was significantly downregulated in a time-dependent manner following the initiation of the stimulation with FFAs, which indicated that miR-1908 is likely to be involved in regulating the development of obesity and insulin resistance via increasing insulin sensitivity of human adipocytes.

Studies on DEX and GH have broadened the knowledge on lipid metabolism and insulin sensitivity. Studies have indicated that high levels of glucocorticoids (such as DEX) in the adipose tissue of obese individuals promote glucose uptake and storage of fatty acids by increasing lipoprotein lipase levels $(27)$ and increasing lipogenesis and lipid storage $(28,29)$. 
Furthermore, GH has a pronounced lipolytic effect, particularly on abdominal fat (30). The present study showed that the expression of miR-1908 was slightly altered by stimulation with DEX, although these changes were not statistically significant. By contrast, miR-1908 was downregulated at $4 \mathrm{~h}$ following treatment with $\mathrm{GH}$; however, the effects of the two hormones appeared to become weaker with increasing time. These findings suggest other underlying mechanisms regulating miR-1908 expression, involving multiple metabolic processes.

In conclusion, the present study identified a new role of obesity-associated cytokines, which are able to alter miR-1908 expression. It remains to be elucidated what accounts for the alteration in miR-1908 expression in response to different adipokines, FFAs and hormones. The mechanisms underlying the alteration in miR-1908 expression have not been clearly linked to specific obesity-related cytokines. However, this is likely to be an important focus of further studies.

\section{Acknowledgements}

The present study was supported by grants from the National Key Basic Research Program of China (no. 2013CB530604), the National Natural Science Foundation of China (no. 81100618), the Natural Science Foundation of Jiangsu Province China (no. BK2011107), the Program for Innovative Research Teams of Jiangsu Province (no. LJ201108) and the Nanjing Technological Development Program (no. 201104013).

\section{References}

1. Ebbeling CB, Pawlak DB and Ludwig DS: Childhood obesity: public-health crisis, common sense cure. Lancet 360: 473-482, 2002.

2. Spiegelman BM and Flier JS: Obesity and the regulation of energy balance. Cell 104: 531-543, 2001.

3. Klaus S: Adipose tissue as a regulator of energy balance. Curr Drug Targets 5: 241-250, 2004.

4. Qatanani M and Lazar MA: Mechanisms of obesity-associated insulin resistance: many choices on the menu. Genes Dev 21: $1443-1455,2007$

5. Trayhurn P, Wang B and Wood IS: Hypoxia in adipose tissue: a basis for the dysregulation of tissue function in obesity? Br J Nutr 100: 227-235, 2008

6. Kim KH, Lee K, Moon YS and Sul HS: A cysteine-rich adipose tissue-specific secretory factor inhibits adipocyte differentiation. J Biol Chem 276: 11252-11256, 2001.

7. Steppan CM, Bailey ST, Bhat S, et al: The hormone resistin links obesity to diabetes. Nature 409: 307-312, 2001.

8. Krützfeldt J and Stoffel M: MicroRNAs: a new class of regulatory genes affecting metabolism. Cell Metab 4: 9-12, 2006.

9. Tang X, Tang G and Ozcan S: Role of microRNAs in diabetes. Biochim Biophys Acta 1779: 697-701, 2008.

10. Poy MN,Eliasson L, Krutzfeldt J, et al: A pancreatic islet-specific microRNA regulates insulin secretion. Nature 432: 226-230, 2004.
11. Lovis P, Roggli E, Laybutt DR, et al: Alterations in microRNA expression contribute to fatty acid-induced pancreatic beta-cell dysfunction. Diabetes 57: 2728-2736, 2008.

12. Bar M, Wyman SK, Fritz BR, et al: MicroRNA discovery and profiling in human embryonic stem cells by deep sequencing of small RNA libraries. Stem Cells 26: 2496-2505, 2008.

13. Wellen KE, Fucho R, Gregor MF, et al: Coordinated regulation of nutrient and inflammatory responses by STAMP2 is essential for metabolic homeostasis. Cell 129: 537-548, 2007.

14. Kralisch S, Klein J, Lossner U, et al: Interleukin-6 is a negative regulator of visfatin gene expression in 3T3-L1 adipocytes. Am J Physiol Endocrinol Metab 289: E586-E590, 2005.

15. Rosen ED and Spiegelman BM: Adipocytes as regulators of energy balance and glucose homeostasis. Nature 444: 847-853, 2006.

16. Guilherme A, Virbasius JV, Puri V and Czech MP: Adipocyte dysfunctions linking obesity to insulin resistance and type 2 diabetes. Nat Rev Mol Cell Biol 9: 367-377, 2008.

17. Pencheva N, Tran H, Buss C, et al: Convergent multi-miRNA targeting of ApoE drives LRP1/LRP8-dependent melanoma metastasis and angiogenesis. Cell 151: 1068-1082, 2012.

18. Long C, Jiang L, Wei F, et al: Integrated miRNA-mRNA analysis revealing the potential roles of miRNAs in chordomas. PLoS One 8: e66676, 2013.

19. Jin JC, Jin XL, Zhang X, Piao YS and Liu SP: Effect of OSW-1 on microRNA expression profiles of hepatoma cells and functions of novel microRNAs. Mol Med Rep 7: 1831-1837, 2013.

20. Bastard JP, Maachi M, Van Nhieu JT, et al: Adipose tissue IL-6 content correlates with resistance to insulin activation of glucose uptake both in vivo and in vitro. J Clin Endocrinol Metab 87: 2084-2089, 2002.

21. Liu S, Yang Y and Wu J: TNF $\alpha$-induced up-regulation of miR-155 inhibits adipogenesis by down-regulating early adipogenic transcription factors. Biochem Biophys Res Commun 414: 618-624, 2011.

22. Steppan CM, Bailey ST, Bhat S, et al: The hormone resistin links obesity to diabetes. Nature 409: 307-312, 2001.

23. Holcomb IN, Kabakoff RC, Chan B, et al: FIZZ1, a novel cysteine-rich secreted protein associated with pulmonary inflammation, defines a new gene family. EMBO J 19: 4046-4055, 2000.

24. Maffei M, Halaas J, Ravussin E, et al: Leptin levels in human and rodent: measurement of plasma leptin and ob RNA in obese and weight-reduced subjects. Nat Med 1: 1155-1161, 1995.

25. Boden G: Role of fatty acids in the pathogenesis of insulin resistance and NIDDM. Diabetes 46: 3-10, 1997.

26. Bergman RN and Ader M: Free fatty acids and pathogenesis of type 2 diabetes mellitus. Trends Endocrinol Metab 11: 351-356, 2000.

27. Fried SK, Russell CD, Grauso NL and Brolin RE: Lipoprotein lipase regulation by insulin and glucocorticoid in subcutaneous and omental adipose tissues of obese women and men. J Clin Invest 92: 2191-2198, 1993.

28. Lee MJ, Gong DW, Burkey BF and Fried SK: Pathways regulated by glucocorticoids in omental and subcutaneous human adipose tissues: a microarray study. Am J Physiol Endocrinol Metab 300: E571-E580, 2011.

29. Yu CY, Mayba O, Lee JV, et al: Genome-wide analysis of glucocorticoid receptor binding regions in adipocytes reveal gene network involved in triglyceride homeostasis. PLoS One 5: e15188, 2010.

30. Gravhølt CH, Schmitz O, Simonsen L, Bülow J, Christiansen JS and Møller N: Effects of a physiological GH pulse on interstitial glycerol in abdominal and femoral adipose tissue. Am J Physiol 277: E848-E854, 1999. 